\title{
Applicability of Clinical Decision Support in Management among Patients Undergoing Cardiac Surgery in Intensive Care Unit: A Systematic Review
}

\author{
Miguel Pereira ${ }^{1,2}$, Patricia Concheiro-Moscoso ${ }^{3, *(D)}$, Alexo López-Álvarez ${ }^{1}$, Gerardo Baños ${ }^{1}$, Alejandro Pazos ${ }^{2,4}$ \\ and Javier Pereira ${ }^{3,4}$ (D)
}

check for

updates

Citation: Pereira, M.;

Concheiro-Moscoso, P.

López-Álvarez, A.; Baños, G.; Pazos,

A.; Pereira, J. Applicability of Clinical

Decision Support in Management

among Patients Undergoing Cardiac

Surgery in Intensive Care Unit: A

Systematic Review. Appl. Sci. 2021, 11,

2880. https://doi.org/10.3390/app

11062880

Academic Editor: José Machado

Received: 19 February 2021

Accepted: 20 March 2021

Published: 23 March 2021

Publisher's Note: MDPI stays neutral with regard to jurisdictional claims in published maps and institutional affiliations.

Copyright: (C) 2021 by the authors Licensee MDPI, Basel, Switzerland This article is an open access article distributed under the terms and conditions of the Creative Commons Attribution (CC BY) license (https:// creativecommons.org/licenses/by/ $4.0 /)$
1 Service of Anesthesiology, Resuscitation, Intensive Care, Álvaro Cunqueiro Hospital, 36213 Vigo, Spain; miguel.angel.pereira.loureiro@sergas.es (M.P.); alexo.lopez.alvarez@sergas.es (A.L.-Á.); gerardo.banos.rodriguez@sergas.es (G.B.)

2 CITIC, RNASA-IMEDIR Group, Computer Science Faculty, University of A Coruña, Elviña, 15071 A Coruña, Spain; alejandro.pazos@udc.es

3 CITIC, TALIONIS Group, Elviña Campus, University of A Coruña, 15071 A Coruña, Spain; javier.pereira@udc.es

4 Biomedical Research Institute of A Coruña (INIBIC), University Hospital Complex of A Coruña (CHUAC), 15006 A Coruña, Spain

* Correspondence: patricia.concheiro@udc.es; Tel.: +34-881-015-870

Abstract: The advances achieved in recent decades regarding cardiac surgery have led to a new risk that goes beyond surgeons' dexterity; postoperative hours are crucial for cardiac surgery patients and are usually spent in intensive care units (ICUs), where the patients need to be continuously monitored to adjust their treatment. Clinical decision support systems (CDSSs) have been developed to take this real-time information and provide clinical suggestions to physicians in order to reduce medical errors and to improve patient recovery. In this review, an initial total of 499 papers were considered after identification using PubMed, Web of Science, and CINAHL. Twenty-two studies were included after filtering, which included the deletion of duplications and the exclusion of titles or abstracts that were not of real interest. A review of these papers concluded the applicability and advances that CDSSs offer for both doctors and patients. Better prognosis and recovery rates are achieved by using this technology, which has also received high acceptance among most physicians. However, despite the evidence that well-designed CDSSs are effective, they still need to be refined to offer the best assistance possible, which may still take time, despite the promising models that have already been applied in real ICUs.

Keywords: clinical decision support; computerized physician order entry; intensive care units; cardiac surgery

\section{Introduction}

Advances in cardiac surgery have enabled the performance of these procedures in patients with the most complex cardiac pathologies and with the highest perioperative risks. These patients are likely to experience complications during the postoperative period. Cardiogenic shock (CS), low cardiac output syndrome (LCOS), stroke, kidney failure, gastrointestinal problems, and respiratory distress are the main issues that may arise during this period, entailing the highest mortality [1-3].

Patients undergoing heart surgery require long stays in intensive care units (ICUs), compared to other types of surgery, due to the aforementioned complications $[4,5]$. These include vasospasm, altered platelet-endothelial cell interactions, and a generalized inflammatory response due to blood contacting the synthetic surfaces of the bypass equipment [6-8]. The result is low flow in the microcirculation of the heart, brain, and other organs, which may lead to organ dysfunction $[9,10]$. In addition, these patients demand 
the use of broad resources during their stay, such as high-level surveillance and monitoring and a quick analysis of the parameters or adjustments in their medical treatment $[11,12]$. The assistance of vital support for these patients is made through the maintenance of vital signs in a target range, the coordination of early therapy directed by objectives in cardiogenic shock, and the hemodynamic stabilization of LCOS. These techniques can speed up postoperative recovery, decrease hospital stays or the use of mechanical ventilation, and reduce ICU days $[13,14]$.

In ICUs, physicians must control these parameters, care for subjects' needs, and prevent complications in order to achieve the optimal conditions of these patients. Therefore, professionals must make elaborate decisions in some situations and make modifications in treatment [15-17]. These situations cause high pressure and intense burden that can cause medical errors and may negatively influence patients' outcomes $[18,19]$. According to Farzi et al., ICU patients are exposed to an average of 1.7 errors per day; specifically, medication errors represent $78 \%$ of serious medical errors [20]. The application of artificial intelligence techniques can provide support to health professionals in decision making related to the treatment of patients [21,22]. The use of clinical decision support systems (CDSSs) can be very appropriate, supporting doctors to improve the clinical progress of patients [23,24]. The development and impact of these systems in the different fields of medicine have been very important [25].

\subsection{Background of Decision Support Systems}

CDSSs are programs based on artificial intelligence (AI) and machine learning (ML) in statistical patterns [26]. CDSSs are a tool increasingly used by clinicians and can involve difficulties in understanding the logic used by AI or integrating different clinical devices [27]. CDSSs also have two other classifications: active or passive based on the design and action of the system. The temporal classification depends on the system's moment of intervention [28].

One of the main objectives of CDSSs is the analysis of patient databases, the extraction of prognostic variables, and the determination of factors to know a patient's evolution [29]. Accordingly, several studies have focused on the Medical Information Mart for Intensive Care III (MIMIC-III), being the largest free access clinical database associated with ICUs [30]. Reports such as those by Bashar et al. have highlighted that MIMIC-III, using a large amount of data, including laboratory tests, procedures, medications, caregivers' notes, image reports, and mortality, allows us to improve relevant clinical outcomes [31,32].

Another type of CDSS focuses on patient safety and drug administration [33]. The Computerized Physician Order Entry (CPOE) offers support to avoid errors in the dosages and improves the adjustment according to a patient's comorbidities [34,35]. Databases are also important in ICUs, because they can enhance learning about the knowledge of the evolution and act in advance to prevent or act in each clinical situation [36]. Analysis of data has provided prognostic or evolutionary factors that have allowed the improvement of clinical results [37]. CDSSs can analyze different information obtained from electronic health records (EHRs) such as the sociodemographic, social, and epidemiological data of patients [38]. EHRs create alerts related to early diagnosis and trends that warn about bad prognosis indicators, allowing early modifications in treatment and modifications in clinical evolution $[34,39]$. CDSSs can be combined with other devices. Some studies have concluded that the combination of CDSSs and CPOE can be considered the most powerful tool for the prevention and reduction in potentially dangerous errors and for greater adjustment according to a patient's comorbidities [40,41].

Some reviews related to CDSSs have been conducted, examining the outcomes associated with CDSSs and CPOE in inpatient settings, but few have focused on the impact that these systems have on cardiac patients in ICUs. Reviews focused on cardiac patients refer only to the economic costs and benefits of CDSSs [42,43]. Another one of these reviews focused on assessing the costs of hospitalization [44]. McKibbon et al. reviewed the effectiveness of these tools on patients in ICUs [45]. Sutton et al. analyzed the benefits and risks 
of CDSSs under a global point of view [46]. The remaining reviews focused specifically on pediatric patients [47-49].

\subsection{Objectives}

Given the importance of knowing the impact of these tools, this review aimed to determine the impact of clinical decision systems on cardiac patients in ICUs. The specific objectives were: (1) to examine and describe the evolution, detection of medical complications, interventions, and treatment response in the postoperative period of cardiac surgery; (2) to describe the rating and satisfaction of health professionals regarding the use of decision systems in ICUs.

\section{Materials and Methods}

The authors conducted this review between 2019 and 2020. This review was guided following the Preferred Reporting Items for Systematic Reviews and Meta-Analyses (PRISMA) statement [50] (see File S1). Relevant studies were selected and analyzed regarding clinical decision support, and a summary of their findings is shown in the Results section.

\subsection{Eligibility Criteria}

In this review, we decided to include only those studies that (1) studied ICU patients of any age with cardiac pathologies and associated problems; (2) analyzed the use of EHRs, CPOE, or MIMIC-III in the data systems' inpatient follow-up; (3) described the combination of CDSSs with previous systems for the improvement of healthcare; (4) provided predictive values for the implementation of these tools in ICUs. Articles that did not meet the following requirements were excluded: (1) articles not published in English, (2) articles without metadata, and (3) studies not published between 2001 and 2020.

\subsection{Search Strategy}

A search was conducted to find relevant published literature related to alert systems and cardiac patients in ICUs (2001-present). The search was performed on three databases: PubMed, Web of Science, and CINAHL (see Table S1). Moreover, scientific meetings proceedings or textbooks on Google Scholar were reviewed to identify significant publications about these topics.

The selection of studies was carried out through an iterative process to identify possible additional studies. In addition, the Boolean operators "OR" and "AND" were used, and some filters such as English language restrictions and publication date restrictions were employed.

The search combined different controlled terms (Mesh) (see Appendix A) for each database, as well as natural language. The main terms used for the search were: "Intensive Care Units" OR "Critical Care") AND ("Artificial Intelligence" OR "Big Data") AND ("Electronic Medical Record" OR "Computerized Medical Record" OR "Clinical Decision Support" OR "Computerized physician order entry" OR "Database") AND ("cardiogenic shock" OR "post-cardiac"). In addition, some additional articles were found for possible inclusion in the review through the reference section of full-text articles and related systematic revisions.

\subsection{Study Selection}

A total of 499 results were obtained in the literature search, including 462 from the search and 37 from the bibliographies of other studies. After eliminating duplicates, two authors read the titles and abstracts generated by the search strategy independently, but at the same time, in order to identify eligible articles and to maintain consistency in the review. Thus, they excluded all studies that did not fulfill the selection criteria determined in the review. When the eligibility and relevance of articles were unclear, they were discussed with the primary authors, who examined in detail the study according to the eligibility criteria. In some situations, they contacted the authors of these researchers for 
the clarification of some questions. So, the authors excluded 301 articles because they were not focused on the review topic.

For the first review, 349 articles were selected, whereas 48 were collected in the second review; finally, 22 results were included. In the second and third revisions, the authors evaluated the full texts and determined the final set of included studies. Figure 1 shows the selection process.

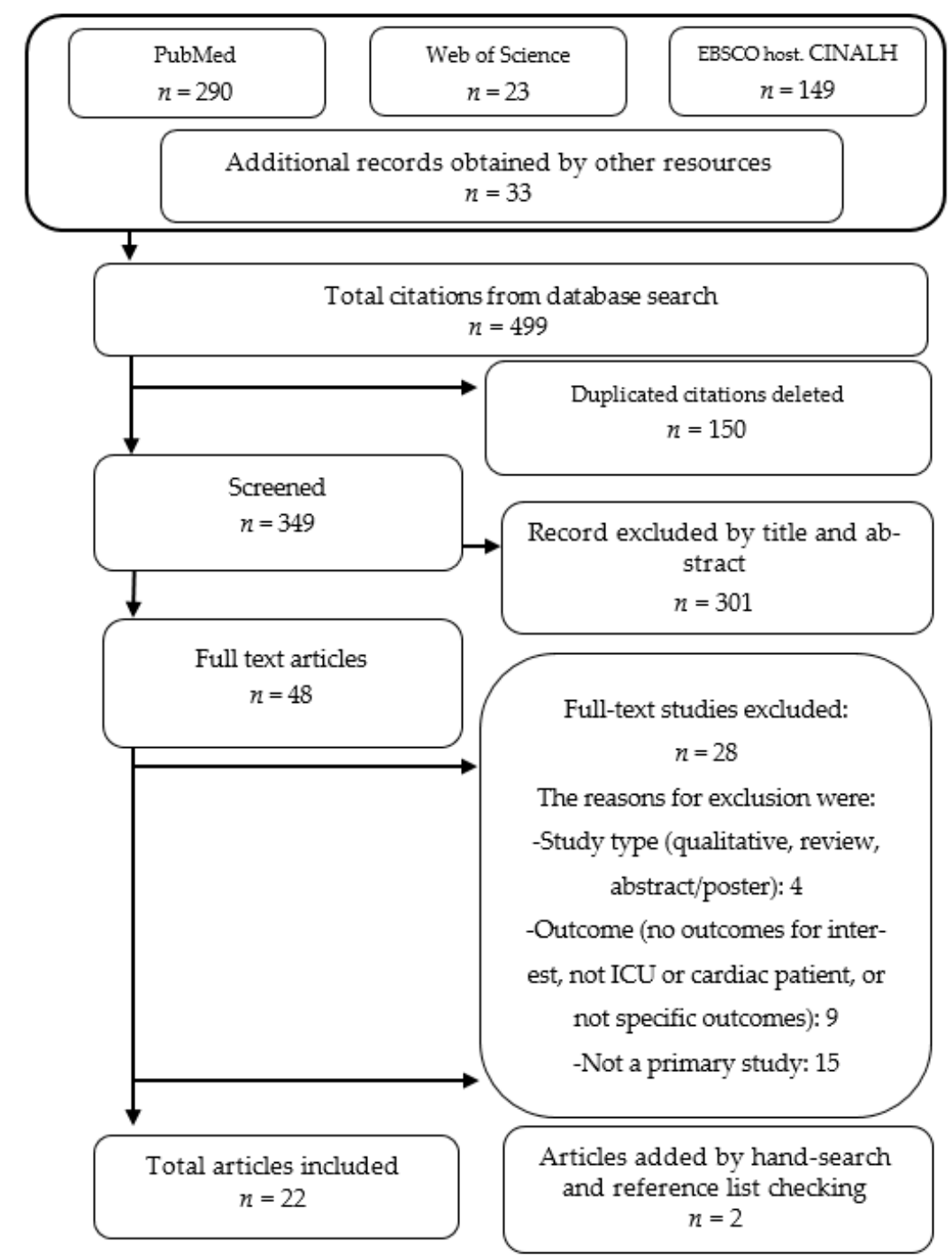

Figure 1. Search and selection flow diagram. ICU, intensive care unit.

\subsection{Data Extraction and Quality Assessment}

Two researchers independently undertook data abstraction from each study. Data were abstracted onto a customized data extraction sheet. The variables included: author and year; the title of the study; country of origin; type and number sample; event identified; type of CDSS; study associated with the database, CPOE, and EHR; description (aim of study and results). The key findings from each study were summarized and presented in tables.

The reviewers coded the variables and resolved any disputes through mutual discussion. We followed three main steps in conducting an interpretive synthesis of our findings: (1) noting the range of functions and the uses of alert systems to promote/improve the situation in ICUs in cardiac patients, (2) developing a synthesis of the findings of included studies, and (3) exploring the relationships in the findings. Automated alerts were used all along the study process in order to keep the review up to date. 
The reviewers assessed the methodological quality of the included studies, based on the criteria of the Effective Public Health Practice Project (EPHPP). This tool was employed for evaluating quantitative studies by previous systematic reviews. Studies are rated based on six components: (a) selection bias, (b) study design, (c) confounders, (d) blinding, (e) data collection methods, and (f) withdrawal and drop-outs.

\subsection{Statistical Analysis}

Each study was classified according to whether it was a CDSS, CPOE, EHR, or database system, as well as a combination of these decision support systems. On the contrary, the studies were grouped by the measurement of the results; thus, they were grouped according to development forecast, medication errors, warning systems, standardization of the protocols, adjustment to the objectives, cost reduction, and acceptance by health professionals.

\section{Results}

\subsection{Study Characteristics}

Twenty-two studies met our inclusion criteria. Table 1 summarizes and shows the characteristics of the studies. Fourteen studies evaluated the functionality of CDSSs in ICUs [51-64], three examined the applicability of databases in ICUs [65-67], one studied investigated the usefulness of EHRs [68], and another one considered CPOE [69]. Lastly, three analyzed the function of combinations of CDSS/CPOE and CDSS/EHR [70-72].

Fifteen studies involved patients over 18 years [51-55,57-59,61,64-69], five studies focused on pediatric patients [56,63,70-72], one used data from both populations [62], and examined professionals [60]. Most studies were conducted in the United States [51,52,55,56,58,62,65-68], Germany [64,72], and the United Kingdom [53,59,63]. Moreover, one was developed each in Spain [69], Israel [71], France [70], Australia [60], Sweden [61], Japan [54], and Canada [57].

The publication dates of these studies ranged from 2006 to 2018. Seven studies focused on the development and validation of information systems [51,53,57,59,64,66,72], five studies used retrospective analysis [52,55,56,58,67], three were prospective cohort studies $[63,69,71]$, two studies conducted had an experimental design $[60,65]$, and one was a controlled trial $[54,61]$; the remaining were a performance study [70], a multicenter study [62], and an observational cohort study [68].

The results of this review were organized according to the application area (see Table 2). Therefore, they were grouped into six main blocks: development forecast, medication errors, warning systems, standardization and compliance with protocols, precise adjustment to objectives, cost reduction, and acceptance. Table 2 shows the classification of the results. 
Table 1. Summary of the data extracted from the 22 selected studies.

\begin{tabular}{|c|c|c|c|c|c|c|c|c|c|c|}
\hline \multirow{2}{*}{ Reference } & \multirow{2}{*}{ Country } & \multicolumn{2}{|c|}{ Sample } & \multirow{2}{*}{ Event Identified } & \multicolumn{4}{|c|}{ Associated to } & \multicolumn{2}{|c|}{ Description } \\
\hline & & Type & Number & & CDSS & CPOE & Database & EHR & Purpose of the Study & Main Findings \\
\hline $\begin{array}{l}\text { Armada et al., } \\
2014 \text { [69] }\end{array}$ & Spain & Adult patients & 137 & $\begin{array}{l}\text { Cardiogenic shock, } \\
\text { acute coronary } \\
\text { syndrome, and } \\
\text { malignant arrhythmias }\end{array}$ & & $\mathbf{x}$ & & & $\begin{array}{l}\text { This study analyzed the } \\
\text { effects of the } \\
\text { Computerized Physician } \\
\text { Order Entry (CPOE) } \\
\text { system in cardiac patients } \\
\text { by detecting medication } \\
\text { errors and evaluating the } \\
\text { use of electronic } \\
\text { prescription by } \\
\text { health professionals. }\end{array}$ & $\begin{array}{l}\text { The results concluded } \\
\text { that CPOE was safe in } \\
\text { practice and was well } \\
\text { received by health } \\
\text { professionals, and its use } \\
\text { reduced errors } \\
\text { in the prescription. }\end{array}$ \\
\hline $\begin{array}{l}\text { Aushev et al., } \\
2018 \text { [65] }\end{array}$ & USA & Adult patients & 75 & $\begin{array}{l}\text { Cardiogenic shock } \\
\text { and septic shock }\end{array}$ & & & $\mathbf{x}$ & & $\begin{array}{l}\text { The aim of the study was } \\
\text { to identify clinical } \\
\text { features that can predict } \\
\text { mortality associated with } \\
\text { cardiogenic or } \\
\text { septic shock. }\end{array}$ & $\begin{array}{l}\text { This study determined } \\
\text { that the application of } \\
\text { different models for } \\
\text { prediction can } \\
\text { prognosticate the risk of } \\
\text { death in the acute phase } \\
\text { of cardiogenic and } \\
\text { septic shock. }\end{array}$ \\
\hline $\begin{array}{l}\text { Banner et al., } \\
2008 \text { [51] }\end{array}$ & USA & Adult patients & 87 & Respiratory failure & $\mathbf{x}$ & & & & $\begin{array}{l}\text { This study aimed to } \\
\text { validate the advisory } \\
\text { system recommendation, } \\
\text { compared to } \\
\text { the experienced } \\
\text { physician's decision. }\end{array}$ & $\begin{array}{l}\text { The results indicated that } \\
\text { there were not significant } \\
\text { differences in either } \\
\text { system. The advisory } \\
\text { system was well } \\
\text { evaluated due to its } \\
\text { forecasts in settings of } \\
\text { pressure support } \\
\text { ventilation (PSV). }\end{array}$ \\
\hline
\end{tabular}


Table 1. Cont.

\begin{tabular}{|c|c|c|c|c|c|c|c|c|c|c|}
\hline \multirow{2}{*}{ Reference } & \multirow{2}{*}{ Country } & \multicolumn{2}{|c|}{ Sample } & \multirow{2}{*}{ Event Identified } & \multicolumn{4}{|c|}{ Associated to } & \multicolumn{2}{|c|}{ Description } \\
\hline & & Type & Number & & CDSS & CPOE & Database & EHR & Purpose of the Study & Main Findings \\
\hline $\begin{array}{c}\text { Campion et al., } \\
2011 \text { [52] }\end{array}$ & USA & Adult patients & 179,452 & $\begin{array}{l}\text { Emergency general } \\
\text { surgery, vascular } \\
\text { surgery, and cardiac/ } \\
\text { thoracic surgery }\end{array}$ & $\mathbf{x}$ & & & & $\begin{array}{l}\text { The objective of this } \\
\text { study was to determine } \\
\text { the effects and conditions } \\
\text { resulting from nurses' } \\
\text { override of clinical } \\
\text { decision support system } \\
\text { (CDSS) recommendations } \\
\text { in ICUs. }\end{array}$ & $\begin{array}{l}\text { The study concluded that } \\
\text { the nurses accepted } \\
\text { among } 95 \% \text { of dosing } \\
\text { recommendations. The } \\
\text { evaluation of the } \\
\text { frequency, direction, and } \\
\text { resistance of the intensive } \\
\text { insulin therapy (IIT) of } \\
\text { the CDSS overrides may } \\
\text { be interesting for the } \\
\text { health professionals } \\
\text { and researchers. }\end{array}$ \\
\hline $\begin{array}{c}\text { Denaï et al., } \\
2009 \text { [53] }\end{array}$ & $\begin{array}{l}\text { United } \\
\text { Kingdom }\end{array}$ & Adult patients & 7 & $\begin{array}{l}\text { Impaired cardiac } \\
\text { function }\end{array}$ & $\mathbf{x}$ & & & & $\begin{array}{l}\text { The aim of the study was } \\
\text { to develop a CDSS for } \\
\text { clinicians' decision } \\
\text { making in post-cardiac } \\
\text { surgery patients } \\
\text { weaned from } \\
\text { cardiopulmonary bypass. }\end{array}$ & $\begin{array}{l}\text { The study showed good } \\
\text { feasibility for applying } \\
\text { CDSS to control the } \\
\text { cardiovascular system in } \\
\text { post-surgery patient. }\end{array}$ \\
\hline $\begin{array}{l}\text { Gouyon et al., } \\
2017 \text { [70] }\end{array}$ & France & $\begin{array}{l}\text { Pediatric } \\
\text { patients }\end{array}$ & 760 & Lower gestational age & $\mathbf{x}$ & $\mathbf{x}$ & & & $\begin{array}{l}\text { This project evaluated the } \\
\text { performance of the } \\
\text { CDSS/CPOE } \\
\text { combination, using the } \\
\text { out-of-range dose rate. }\end{array}$ & $\begin{array}{l}\text { The conclusion was that } \\
\text { the CDSS/CPOE system } \\
\text { was feasible for the } \\
\text { prescription of all drugs } \\
\text { in ICUs. This system } \\
\text { allows for the evaluation } \\
\text { and comparison of drugs. }\end{array}$ \\
\hline $\begin{array}{l}\text { Hsu et al., } \\
2013 \text { [54] }\end{array}$ & Japan & Adult patients & 380 & Respiratory failure & $\mathbf{x}$ & & & & $\begin{array}{l}\text { The objective was to } \\
\text { verify the effectiveness of } \\
\text { a CDSS to predict and } \\
\text { reduce the use of } \\
\text { ventilator weaning. }\end{array}$ & $\begin{array}{l}\text { This CDSS was effective } \\
\text { in the identification of the } \\
\text { earliest time of ventilator } \\
\text { weaning for a patient to } \\
\text { resume and sustain } \\
\text { spontaneous breathing. }\end{array}$ \\
\hline
\end{tabular}


Table 1. Cont.

\begin{tabular}{|c|c|c|c|c|c|c|c|c|c|c|}
\hline \multirow{2}{*}{ Reference } & \multirow{2}{*}{ Country } & \multicolumn{2}{|c|}{ Sample } & \multirow{2}{*}{ Event Identified } & \multicolumn{4}{|c|}{ Associated to } & \multicolumn{2}{|c|}{ Description } \\
\hline & & Type & Number & & CDSS & CPOE & Database & EHR & Purpose of the Study & Main Findings \\
\hline $\begin{array}{l}\text { Jalali et al., } \\
2016 \text { [55] }\end{array}$ & USA & Adult patients & 4000 & $\begin{array}{l}\text { Cardiac surgery } \\
\text { and infections }\end{array}$ & $\mathbf{x}$ & & & & $\begin{array}{l}\text { The study's purpose was } \\
\text { to develop a CDSS } \\
\text { algorithm for predicting } \\
\text { the prognostic of patients } \\
\text { in ICUs. }\end{array}$ & $\begin{array}{l}\text { The conclusions } \\
\text { demonstrated that CDSSs } \\
\text { can resolve complex } \\
\text { situations in ICUs. }\end{array}$ \\
\hline $\begin{array}{l}\text { Jalali et al., } \\
2018 \text { [56] }\end{array}$ & USA & $\begin{array}{l}\text { Pediatric } \\
\text { patients }\end{array}$ & 71 & $\begin{array}{l}\text { Periventricular } \\
\text { leukomalacia }\end{array}$ & $\mathbf{x}$ & & & & $\begin{array}{l}\text { The aim was to design a } \\
\text { classifier adaptable to the } \\
\text { patient and incorporated } \\
\text { into the experts' } \\
\text { opinion in the } \\
\text { classification process. }\end{array}$ & $\begin{array}{l}\text { This project collected data } \\
\text { from a highly reliable } \\
\text { digital instrument with } \\
\text { greater frequency, } \\
\text { expanding the set of } \\
\text { features, pre-classifying } \\
\text { patients according } \\
\text { to the diagnosis. }\end{array}$ \\
\hline $\begin{array}{l}\text { Johnson et al., } \\
2016 \text { [66] }\end{array}$ & USA & Adult patients & 38597 & $\begin{array}{l}\text { Coronary disease, } \\
\text { cardiac surgery, trauma, } \\
\text { and surgical procedure }\end{array}$ & & & $\mathbf{x}$ & & $\begin{array}{l}\text { This study wanted to } \\
\text { determine the } \\
\text { accessibility of the } \\
\text { Medical Information Mart } \\
\text { for Intensive Care III } \\
\text { (MIMIC-III) database for } \\
\text { the scientific community. }\end{array}$ & $\begin{array}{l}\text { The study concluded that } \\
\text { the MIMIC-III database } \\
\text { allowed access to ICU } \\
\text { data at an international } \\
\text { level, improving the } \\
\text { quality of academic and } \\
\text { industrial research. }\end{array}$ \\
\hline $\begin{array}{l}\text { Kallet et al., } \\
2007 \text { [57] }\end{array}$ & Canada & Adult patients & NA & $\begin{array}{l}\text { Pulmonary and cardiac } \\
\text { surgery }\end{array}$ & $\mathbf{x}$ & & & & $\begin{array}{l}\text { This paper reviewed the } \\
\text { use of the National } \\
\text { Institutes of Health acute } \\
\text { respiratory distress } \\
\text { syndrome (ARDS) } \\
\text { network positive } \\
\text { end-expiratory pressure } \\
\text { (PEEP)/ inspired oxygen } \\
\text { fraction (FIO2) titration } \\
\text { tables to the treatment of } \\
\text { patients with ARDS. }\end{array}$ & $\begin{array}{l}\text { The study determined } \\
\text { that the PEEP/FIO2 } \\
\text { tables were a } \\
\text { good option for the } \\
\text { treatment of ARDS. }\end{array}$ \\
\hline
\end{tabular}


Table 1. Cont.

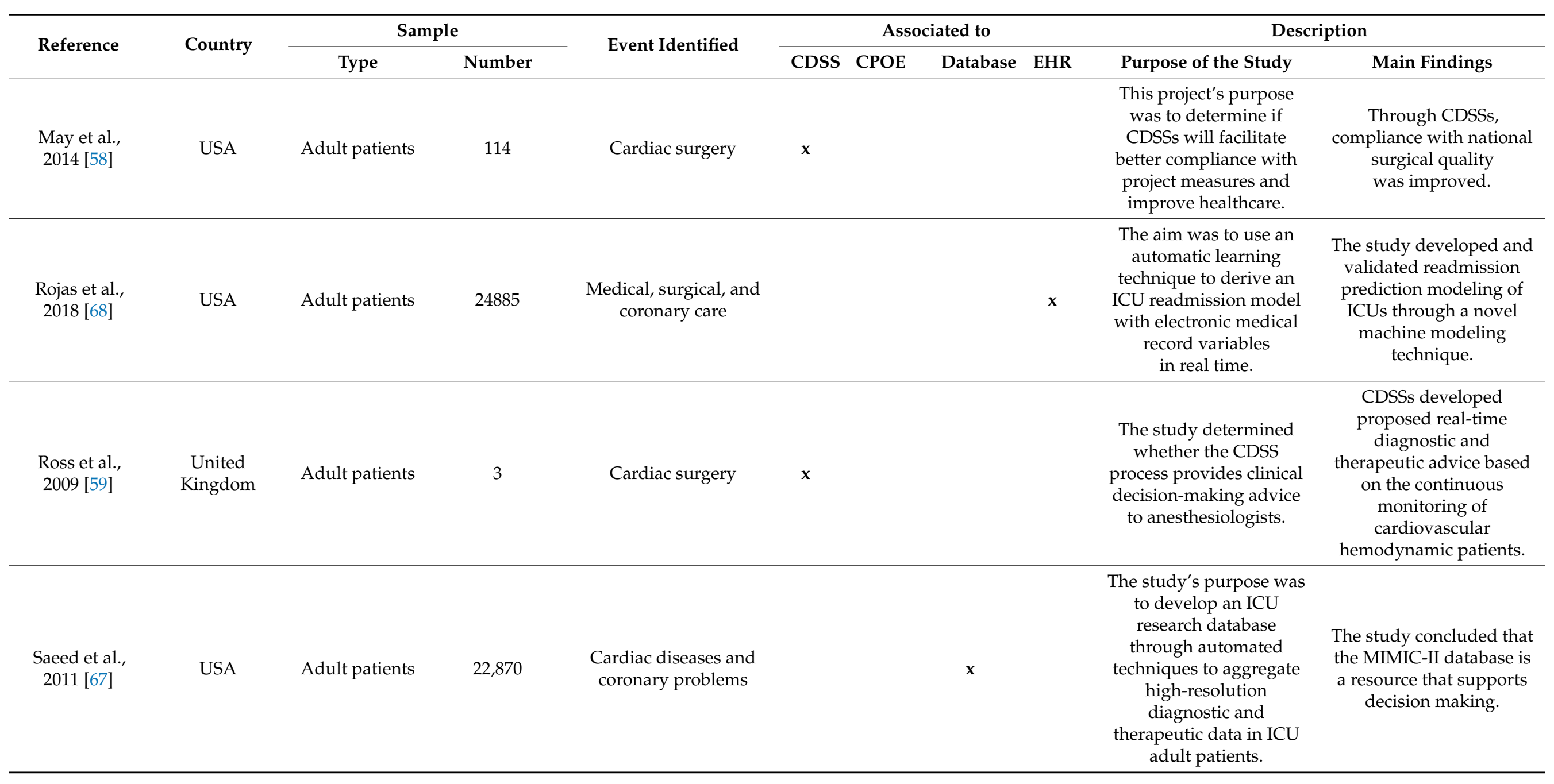


Table 1. Cont.

\begin{tabular}{|c|c|c|c|c|c|c|c|c|c|c|}
\hline \multirow{2}{*}{ Reference } & \multirow{2}{*}{ Country } & \multicolumn{2}{|c|}{ Sample } & \multirow{2}{*}{ Event Identified } & \multicolumn{4}{|c|}{ Associated to } & \multicolumn{2}{|c|}{ Description } \\
\hline & & Type & Number & & CDSS & CPOE & Database & EHR & Purpose of the Study & Main Findings \\
\hline $\begin{array}{l}\text { Sintchenko } \\
\text { et al., } 2006 \text { [60] }\end{array}$ & Australia & $\begin{array}{c}\text { Specialists } \\
\text { Intensive Care }\end{array}$ & 31 & None & $x$ & & & & $\begin{array}{l}\text { The aim was to examine } \\
\text { the impact of CDSSs for } \\
\text { ICU antibiotic } \\
\text { prescribing. }\end{array}$ & $\begin{array}{l}\text { The study concluded that } \\
\text { CDSSs are an important } \\
\text { factor in the process of } \\
\text { complex decisions; it } \\
\text { supported decision } \\
\text { making and the } \\
\text { functionality of } \\
\text { different tasks. }\end{array}$ \\
\hline $\begin{array}{l}\text { Sondergaard } \\
\text { et al., } 2012 \text { [61] }\end{array}$ & Sweden & Adult patients & 24 & $\begin{array}{c}\text { Pancreatic cancer, heart } \\
\text { transplants, and } \\
\text { intestinal carcinoid } \\
\text { diseases }\end{array}$ & $\mathbf{x}$ & & & & $\begin{array}{c}\text { The study's purpose was } \\
\text { to research the } \\
\text { performance of CDSSs in } \\
\text { achieving some } \\
\text { parameters in patients } \\
\text { with major } \\
\text { abdominal surgery. }\end{array}$ & $\begin{array}{l}\text { The results demonstrated } \\
\text { that there was a } \\
\text { concordance between the } \\
\text { recommend treatments of } \\
\text { CDSSs and the treatments } \\
\text { of anesthetists. }\end{array}$ \\
\hline $\begin{array}{l}\text { Thompson } \\
\text { et al., } 2008 \text { [62] }\end{array}$ & USA & $\begin{array}{l}\text { All adult and } \\
\text { pediatric } \\
\text { patients }\end{array}$ & 148 & $\begin{array}{c}\text { Pulmonary, } \\
\text { neurological, } \\
\text { cardiovascular, } \\
\text { gastrointestinal, and } \\
\text { multisystem diseases }\end{array}$ & $\mathbf{x}$ & & & & $\begin{array}{l}\text { The aim was to determine } \\
\text { the effectiveness, } \\
\text { satisfaction, and } \\
\text { acceptance of } \\
\text { eProtocol-insulin in ICUs. }\end{array}$ & $\begin{array}{l}\text { eProtocol-insulin was } \\
\text { generally accepted in } \\
\text { ICUs. This study } \\
\text { demonstrated that it can } \\
\text { be a decision-support tool } \\
\text { and a method for use in } \\
\text { practices and } \\
\text { clinical research. }\end{array}$ \\
\hline $\begin{array}{l}\text { Vardi et al., } \\
2007 \text { [71] }\end{array}$ & Israel & $\begin{array}{l}\text { Pediatric } \\
\text { patients }\end{array}$ & 105 & $\begin{array}{l}\text { Congenital heart } \\
\text { diseases, metabolic } \\
\text { diseases, multiple } \\
\text { traumas, head traumas, } \\
\text { respiratory diseases, } \\
\text { and sepsis }\end{array}$ & $\mathbf{x}$ & $\mathbf{x}$ & & & $\begin{array}{l}\text { The objective was to } \\
\text { determine the impact of } \\
\text { CDSS/CPOE in the } \\
\text { preventions of medical } \\
\text { errors in medication } \\
\text { resuscitation orders. }\end{array}$ & $\begin{array}{l}\text { The project considered } \\
\text { that this warning system } \\
\text { is a support tool in drug } \\
\text { treatment, leading to } \\
\text { medical error reductions. }\end{array}$ \\
\hline
\end{tabular}


Table 1. Cont.

\begin{tabular}{|c|c|c|c|c|c|c|c|c|c|c|}
\hline \multirow{2}{*}{ Reference } & \multirow{2}{*}{ Country } & \multicolumn{2}{|c|}{ Sample } & \multirow{2}{*}{ Event Identified } & \multicolumn{4}{|c|}{ Associated to } & \multicolumn{2}{|c|}{ Description } \\
\hline & & Type & Number & & CDSS & CPOE & Database & EHR & Purpose of the Study & Main Findings \\
\hline $\begin{array}{l}\text { Warrick et al., } \\
2011 \text { [63] }\end{array}$ & $\begin{array}{l}\text { United } \\
\text { Kingdom }\end{array}$ & $\begin{array}{l}\text { Pediatric } \\
\text { patients }\end{array}$ & NA & None & $x$ & & & & $\begin{array}{l}\text { The study wanted to } \\
\text { determine the effect of } \\
\text { electronic prescribing (EP) } \\
\text { on prescribing errors and } \\
\text { doses in pediatric ICUs. }\end{array}$ & $\begin{array}{l}\text { The study determined } \\
\text { that EP increases } \\
\text { medication safety in } \\
\text { pediatric ICUs. }\end{array}$ \\
\hline $\begin{array}{c}\text { Wulff et al., } \\
2018 \text { [72] }\end{array}$ & Germany & $\begin{array}{c}\text { Pediatric } \\
\text { patients }\end{array}$ & 16 & None & $\mathbf{x}$ & & & $\mathbf{x}$ & $\begin{array}{l}\text { The aim was to develop } \\
\text { and evaluate an open } \\
\text { electronic health record } \\
\text { (EHR) for systemic } \\
\text { inflammatory response } \\
\text { syndrome (SIRS) } \\
\text { detection in } \\
\text { pediatric ICUs. }\end{array}$ & $\begin{array}{l}\text { The study found that the } \\
\text { inclusion of an open EHR } \\
\text { in a CDSS can bridge the } \\
\text { interoperability gap } \\
\text { between local } \\
\text { infrastructure in } \\
\text { said CDSS. }\end{array}$ \\
\hline $\begin{array}{c}\text { Zaslansky } \\
\text { et al., } 2014 \text { [64] }\end{array}$ & Germany & $\begin{array}{l}\text { Adults } \\
\text { patients }\end{array}$ & 40,898 & Pain & $\mathbf{x}$ & & & & $\begin{array}{l}\text { The aim was to develop } \\
\text { and validate a medical } \\
\text { registry to measure and } \\
\text { identify some aspects } \\
\text { regarding pain. }\end{array}$ & $\begin{array}{l}\text { This pain-related CDSS } \\
\text { provides health } \\
\text { professionals with easy } \\
\text { access to data on the } \\
\text { clinical management of } \\
\text { pain, supporting the } \\
\text { decision-making process }\end{array}$ \\
\hline
\end{tabular}


Table 2. Summary of the results field of the study.

\begin{tabular}{cc}
\hline Patient & Application Area \\
\hline Before admission & Forecast and evolutionary prediction \\
\hline During admission & Reduction in medical errors \\
\cline { 2 - 2 } & $\begin{array}{c}\text { Alerts, fast detection of alterations, } \\
\text { and treatment settings }\end{array}$ \\
\cline { 2 - 2 } After admission & $\begin{array}{c}\text { Achievement of objectives and } \\
\text { maintenance in established ranges }\end{array}$ \\
\cline { 2 - 2 } & Reduction in health costs \\
\hline
\end{tabular}

\subsection{Thematic Categories}

\subsubsection{Development Forecast}

Five studies examined the use of CDSSs as a tool to predict the evolution that patients may have after heart surgery [55-57,67,68]. All five positive results obtained on the use of support systems to assess the evolution of patients in ICUs by analyzing multiple biomedical parameters $[55-57,67,68]$. Jalali et al. stated that the use of CDSSs can allow us to detect a rapid deterioration of a patient and be able to predict and achieve better results of concordance compared to classic scales of the sequential organ failure (SOFA) score and the simplified acute physiology score (SAPS) II [55]. The use of CDSSs, through the analysis of variables and clinical data associated with the function of the organs, results in a $45 \%$ higher F-score than the more classic tools (SOFA and SAPS-II are 26 and $29 \%$, respectively) [55].

Another study by Jalali et al. involved the development of a CDSS for the prediction of periventricular leukomalacia, resulting in improved survival rates of neonates who underwent cardiac surgery. Survival rates were improved due to the average reduction in the time between surgery and diagnosis to six days. In addition, the results showed a high F-score (0.8) for the way the system ranks [56].

Rojas et al. assessed the probability of needing readmission in ICUs with the development of a prediction model using automatic learning techniques. With the use of the machine-learning-derived model, a lower area of the curve (0.76) was obtained, which was more favorable than the "Stability and Workload Index for Transfer "(SWIFT) score (0.65) or the "Modified Early Warning Score" (MEWS) (0.58). The results showed that this model better predicted ICU readmission compared to the SWIFT score and the MEWS. In addition, it had a higher area under the receiver operating curve (AUC) for predicting readmissions $(p<0.001)$ [68]. Other studies proved the effectiveness of these support systems in predicting the evolution of the patient in the weaning process and with the MIMIC-II [57,67].

\subsubsection{Medication Errors}

Four studies [63,69-71] focused on the analysis of the performance of support systems, specifically on the tools applied to CPOE systems in the prevention of errors in the pharmacological treatment of patients in ICUs. In general terms, these studies evidence an improvement in hospital care after the use of $\mathrm{CPOE}$, such as a reduction in errors observed after its application $[69,71]$.

Three of the studies indicate clinically significant changes in the incidence of medication errors [69-71]. Vardi's study reported that before CPOE use, there were three errors for every 13,142 orders, while after its application, no medical errors were found [71]. Armada et al. found a reduction in errors from 92 to $98 \%$ in two experimental periods [69]. Gouyon et al. combined CPOE and a CDSS to avoid medicals errors for improving patient care safety. Approximately $30-40 \%$ of neonates had at least one of the licensed prescriptions [70]. 
In addition, the studies refer to the common causes of medical errors $[63,69,70]$. Armada et al. determined that some factors, such as lapses of health professionals, a lack of information, or inappropriate use of the computer system, can cause medical errors [69]. Other studies indicate that medical errors are caused by the inadequate selection of the dosage of some drugs $[63,70]$.

Two studies analyzed the types of errors found; the most frequent errors were found to be mistakes in the name of the drug, the number of doses, or the units of measurement of doses $[69,71]$. These aspects were reduced with the use of support systems. Finally, one study reported that with the applicability of the CPOE system, the time of administration of drugs reduced from $14 \mathrm{~min} 42 \mathrm{~s}$ (standard deviation, 05:03) to $2 \mathrm{~min} 14 \mathrm{~s}$ (standard deviation, 00:39) [71].

\subsubsection{Warning Systems: Early Detection and Early Action}

Four studies analyzed the incorporation of CDSSs into surveillance and continuous analysis to allow the fast detection of clinical alterations [51,58,65,72]. Two studies examined the use of CDSSs in cardiac surgery patients. These systems monitored and controlled different parameters, such as blood glucose levels, or the presence of some conditions, such as the automated systematic inflammatory response syndrome (ARS) [58,72]. One of the studies reported that the system effectively warned healthcare professionals about B-blocker therapy before the operation and alerted them to the B-blocker restart [58]. Wulff et al. demonstrated a high agreement between the system and health professionals. The results showed a sensitivity of 1.00, a specificity of 0.94 , and a kappa of Cohen of 0.92 [72].

Aushev et al. developed an automatic learning algorithm (ShockOmics) for predicting mortality in patients with cardiogenic shock for early detection. The results reported that the system had high sensitivity and specificity. Thus, an early alert reduced the risk of mortality in the acute phase of cardiogenic and septic shock, improving patients evolution [65]. Another study analyzed the applicability of VentAssit as an alert system, which resulted in changes in the pressure support prescription for mechanically ventilated patients using the real-time measurement of power breathing. The results demonstrated an agreement with the intensivist's decision [51].

\subsubsection{Standardization and Compliance with Protocols}

Three studies included in the review examined the use of support systems as a necessary tool in the application and diagnostics of complex protocols $[54,57,64]$. Two studies reported that the application of a CDSS, as an essential tool for different established protocols, can improve decision making and diagnostics compared to traditional protocols [54,57].

Hsu et al. reported that the use of a CDSS helped health professionals to make decisions about those patients who presented a clinical situation that was suitable for being detested [54]. Likewise, these advanced protocols promoted a better evolution of patients through the improvement of the different biomedical parameters [54].

On the contrary, Zaslansky et al. proved CDSSs can be helpful in the diagnosis and the implementation of protocols for the improvement of treatments. The results presented that $60 \%$ of the cases following the recommendations of the protocols. These protocols are characterized by their parameters, such as performance assessment or benchmarking [64].

\subsubsection{Precise Adjustment to Objectives}

Six studies analyzed the applicability of these systems for maintaining biological constants within a more precise target range [51-54,59,61]. Five of these studies reported that the application of CDSSs kept patients' constants stable, improving the evolution of the patients who were submitted to cardiac surgery [51-54,59].

Hsu et al. reported that CDSSs helped to maintain the stability of the biomedical parameters of the patients in the study group compared to those of the patients in the control group, resulting in a statistically significant relationship $(p<0.01)$ [54]. Moreover, Campion 
et al. determined the applicability of a CDSS for administering or adjusting insulin doses. The results showed that the recommended doses were accepted to a greater extent $(83 \%)$ than higher doses $(78 \%)$, with a statistically significant relationship $(p<0.001)$ [52].

Another field of application deals with hemodynamic parameters. Monitors such as pulse wave cardiac output lithium dilution cardiac output (LIDCOPLUS) provide computational intelligence to facilitate clinical decision making. Two studies proved LIDCOPLUS to be useful for patients undergoing cardiac surgery to maintain hemodynamic constants by assessing continuous monitoring and suggesting measures needed to keep them in range. In vasoactive drug infusion, the system modifies the doses or proposes a dose modification, measuring the improvement in the quality and efficiency of healthcare [53,59]. Likewise, VenAssit achieved a range of $84 \%$ by stabilizing six parameters such as plateau pressure, tidal volume, respiratory rate, Wob, tidal end $\mathrm{CO}_{2}$, and $\mathrm{O}_{2}$ saturation [51].

Finally, Sondergaard et al. used a target-directed therapy (TGT) to diagnose and administration a real-time pharmacological treatment regularly used. The results showed that there was no difference in the mean percentage time spent in the target zone $36.7 \%$ in control group and $35.5 \%$ in the intervention group), and there were no differences in the fluid balance, but there was a high level of concordance between both groups [61].

\subsubsection{Cost Reduction}

Three studies analyzed the use of CDSSs in reducing healthcare costs $[65,68,69]$. All the studies reported that CDSSs provide real-time diagnostic and therapeutic advice through the continuous monitoring of patients in cardiovascular dynamics, promoting a reduction in health costs. Its use has reduced medical errors and has shown a hospital stay reduction (length of stay (LOS)) and mortality $[65,68,69]$.

Rojas et al. implemented a model of readmission in the ICU in real time. The results showed that $11 \%$ of the readmissions occurred during hospitalization; there was a greater probability of receiving more interventions and medications, which promoted a higherquality stay [68]. One of the studies examined the use of CPOE in medical error preventions, resulting in a reduction in hospital stays and improved healthcare [69]. Aushev et al. concluded that identifying the most relevant features of patients with cardiogenic shock by CPOE reduces mortality rates and results in improved patient conditions, reduced burden, and reduced hospital care [65].

\subsubsection{Acceptance}

Six studies analyzed the acceptance of health professionals about support systems in clinical practice $[52,53,59,60,62,69]$. Four studies reported that these support systems can be accepted in the different fields of both treatments and diagnoses $[52,53,59,69]$. The recommendations of these support systems were accepted by the majority of critical care professionals, and they were considered a useful tool in clinical practice. Moreover, the combination of these systems was valued positively [69]. On the contrary, few studies showed negative results about the system's use in clinical practice but suggested the system's complexity and the overload of work $[60,62]$.

\section{Discussion}

This review focused on the applicability of CDSSs, databases, CPOE, and EHRs in cardiac surgery patients in ICUs. The objectives were focused on summarizing the recent scientific evidence on this subject in order to investigate clinical decision support systems. Decision-making aids have been studied in different fields and types of patients.

The results showed an emerging area associated with the development forecast. Some studies referred to CDSSs, analyzing the predisposing parameters and supporting the forecast of the evolution and the readmission that a patient may present $[56,67,68]$. CDSSs use multiple parameters to determine the prognostics, such as patient characteristics, comorbidities, reasons for admission, and scales [55,73]. 
Specifically, the studies of Jalali et al. referred to the prediction of development in said studies. Both studies focused on patients with neurocritical and periventricular leukomalacia patients. They reported that a rapid prediction of a patient's development can reduce mortality levels or hospital stay, among others [55,56].

The databases through CDSSs, including the parameters, proved their usefulness in predicting evolution, such as demographic data, laboratory data, and admission diagnoses $[57,67]$. Some reviews support the above. These reviews focused extensively on analyzing the prediction ranges of tools such as databases or CDSSs [74,75].

Another result that emerged strongly in the selected articles was medical errors. Specifically, the tools applied to CPOE systems were assessed in relation to their strong impact on the prevention of drug-related errors [63,69-71]. According to the evidence, CPOE tools prevent the wrong administration of drugs and help to make dosage adjustments considering comorbidities, which are among the most common confounding factors [76-78]. These dose modifications could eventually lead to a reduction in critical events such as cardiorespiratory arrest [71].

In addition, the results indicate that drug administration times were significantly reduced after the use of CPOE. Among the studies that were analyzed, the improvement in healthcare after the use of CPOE is meaningful, since errors of administration were recorded before and after its application, and a reduction was observed [63,69-71]. The reduction in the incidence of drug administration errors and the reduction in time to administration is of paramount importance in the pandemic situation because of the shortage in resources in critical care settings, and it must not be overlooked $[79,80]$. Although this situation does not directly affect the tasks usually performed by physicians or nursing professionals, it is considered one of the most limiting factors in providing the necessary care on time, so any tool capable of alleviating burdens should be considered potentially useful [78].

Moreover, the results suggest that these tools can detect difficulties in a patient's situation for rapid action $[54,64,65]$. Considering the evidence, CDSSs and EHRs allow continuous monitoring for detecting clinical alterations at the precise moment they take place. This is relevant in postoperative patients, as they have a greater risk of suffering significant complications [79].

CDSSs also offer a precise adjustment of dosage or flux to maintain a variable in the desired range [51-54,59,61]. Some examples of the already developed CDSSs on this subject matter belong to the field of hemodynamic advanced measurement devices, such as cardiac output (CO) [53,59]. These studies dealt with the utilization of a CDSS combined with a continuous monitor of cardiovascular function [52,54]. The systems were able to select and advise reasonable treatments under different clinical conditions [51].

These systems are able to select and advise reasonable treatments under different clinical conditions. However, some of the analyzed results showed no significant statistical differences, and the lack of significant differences should not impede the relevance of these findings [61]. It is remarkable to find such high concordance between specialists trained in intensive care and decision support systems and their ability to reach an equivalent fluid balance. As mentioned before, any tool with the ability to perform successfully while keeping high standards of care must be considered potentially useful, since it may allow dedicating human resources to more sophisticated tasks in healthcare.

Finally, the degree of acceptance of systems that report high levels of acceptance was evaluated for these systems for treatment and diagnosis $[60,62]$ Other studies have considered it negative in terms of a lack of confidence in the decisions suggested, as occurs in nursing staff, about the regulation of glucose levels by prolonging the time to accept or reject the suggestion, concluding that these tools represent low impact on their work activities [69]. Doubt then arises about whether the correct implementation of CDSSs, despite their initial investment, guarantees a cost reduction at any hospital, as the shorter the patient needs to stay in ICUs, the lower amount of money will be necessary to invest. 


\section{Conclusions}

In this systematic review, CDSSs were proven to be a useful tool, especially in the three categories of reductions in prescription errors, with a near total in certain types of error reduction, the prediction of evolution and prognosis, with a higher capacity than the scales commonly used to predict readmission and even an in-mortality reduction in the context of infant heart surgery, and in the of costs reduction, by reducing stay times and complications.

In the other categories, i.e., the standardization of protocols, adjustment with a target, warning systems, and acceptance, the results were less consistent and sometimes contradictory. Clarification will have to wait for new systems to be developed, so that their usefulness in ICUs can be assessed.

Supplementary Materials: The following are available online at https://www.mdpi.com/2076-3 417/11/6/2880/s1, File S1: Preferred Reporting Items for Systematic Reviews and Meta-Analyses (PRISMA) checklist; Table S1: Search strategies from each database.

Author Contributions: The authors contributed to this research article in the following ways: conceptualization, M.P., P.C.-M., and J.P.; methodology, M.P. and P.C.-M.; formal analysis, M.P., P.C.-M., A.L.-Á., and J.P.; investigation, M.P., P.C.-M., A.L.-Á., and J.P.; writing—original draft preparation, M.P., P.C.-M., and A.L.-Á.; writing—review and editing: G.B., A.P., and J.P.; visualization and supervision, all authors; funding acquisition, P.C.-M. All authors read and agreed to the published version of the manuscript.

Funding: The authors disclose the receipt of the following financial support for the research, authorship, and/or publication of this article: all of the economic costs involved in the study were borne by the research team. This work was supported in part by grants from the European Social Fund 2014-2020. The Research Centre of the Galician University System (CITIC) and the Galician University System (SUG) obtained funds through the Regional Development Fund (ERDF), with 80\% from the Operational Program ERDF Galicia 2014-2020 and the remaining 20\% from the Secretaría Xeral de Universidades of the Galician University System (SUG). P.C.-M. obtained a scholarship (Ref. ED481A-2019/069) to develop a Ph.D. thesis. Furthermore, the diffusion and publication of this research were funded by the CITIC as a Research Centre by Galician University System with the support previously mentioned (Ref. ED431G-2019/01). In addition, this work was also funded by a grant for the consolidation and structuring of competitive research units (ED431C 2018/49) from the General Directorate of Culture, Education and University Management of Xunta de Galicia, and the CYTED.

Institutional Review Board Statement: Not applicable.

Informed Consent Statement: Not applicable.

Data Availability Statement: The study's data are available to any researcher who contacts the corresponding author, Patricia Concheiro-Moscoso (patricia.concheiro@udc.es).

Conflicts of Interest: The authors declare no conflict of interest. 


\section{Appendix A. Search Terms}

\begin{tabular}{cc}
\hline Keywords & Mesh Terms \\
\hline Intensive Care Units & $\begin{array}{c}\text { Intensive Care Units (Coronary Care Units; } \\
\text { Intensive Care Units, Pediatric; Intensive Care } \\
\text { Units, Neonatal) }\end{array}$ \\
\hline Critical Care & Critical Care (Early Goal-Directed Therapy; \\
Intensive Care)
\end{tabular}

\section{References}

1. Elgharably, H.; Gamaleldin, M.; Ayyat, K.S.; Zaki, A.; Hodges, K.; Kindzelski, B.; Yongue, C.; de la Serna, S.; Perez, J.; Spencer, C.; et al. Serious Gastrointestinal Complications after Cardiac Surgery \& Associated Mortality. Ann. Thorac. Surg. 2020. [CrossRef]

2. Tanner, T.G.; Colvin, M.O. Pulmonary Complications of Cardiac Surgery. Lung 2020, 198, 889-896. [CrossRef]

3. Ghannem, M.; Ahmaidi, S.; Ghannem, L.; Meimoun, P. Infectious and inflammatory complications occurring after cardiac surgery in cardiac rehabilitation centres. Ann. Cardiol. Angeiol. (Paris) 2020, 69, 424-429. [CrossRef] [PubMed]

4. Hassan, A.; Anderson, C.; Kypson, A.; Kindell, L.; Ferguson, T.B.; Chitwood, W.R.; Rodriguez, E. Clinical Outcomes in Patients With Prolonged Intensive Care Unit Length of Stay After Cardiac Surgical Procedures. Ann. Thorac. Surg. 2012, 93, 565-569. [CrossRef]

5. Silberman, S.; Bitran, D.; Fink, D.; Tauber, R.; Merin, O. Very Prolonged Stay in the Intensive Care Unit After Cardiac Operations: Early Results and Late Survival. Ann. Thorac. Surg. 2013, 96, 15-22. [CrossRef] [PubMed]

6. Cho, Y.J.; Nam, K.; Yoo, S.J.; Lee, S.; Bae, J.; Park, J.-Y.; Kim, H.-R.; Kim, T.K.; Jeon, Y. Effects of remote ischemic preconditioning on platelet activation and reactivity in patients undergoing cardiac surgery using cardiopulmonary bypass: A randomized controlled trial. Platelets 2020, 1-9. [CrossRef]

7. Vedel, A.G.; Holmgaard, F.; Rasmussen, L.S.; Langkilde, A.; Paulson, O.B.; Lange, T.; Thomsen, C.; Olsen, P.S.; Ravn, H.B.; Nilsson, J.C. High-target versus low-target blood pressure management during cardiopulmonary bypass to prevent cerebral injury in cardiac surgery patients: A randomized controlled trial. Circulation 2018, 137, 1770-1780. [CrossRef]

8. Abrard, S.; Fouquet, O.; Riou, J.; Rineau, E.; Abraham, P.; Sargentini, C.; Bigou, Y.; Baufreton, C.; Lasocki, S.; Henni, S. Preoperative endothelial dysfunction in cutaneous microcirculation is associated with postoperative organ injury after cardiac surgery using extracorporeal circulation: A prospective cohort study. Ann. Intensive Care 2021, 11, 4. [CrossRef]

9. Rossaint, J.; Berger, C.; Van Aken, H.; Scheld, H.H.; Zahn, P.K.; Rukosujew, A.; Zarbock, A. Cardiopulmonary Bypass during Cardiac Surgery Modulates Systemic Inflammation by Affecting Different Steps of the Leukocyte Recruitment Cascade. PLoS ONE 2012, 7, e45738. [CrossRef]

10. Itagaki, S.; Chikwe, J.P.; Chiang, Y.P.; Egorova, N.N.; Adams, D.H. Long-Term Risk for Aortic Complications After Aortic Valve Replacement in Patients With Bicuspid Aortic Valve Versus Marfan Syndrome. J. Am. Coll. Cardiol. 2015, 65, 2363-2369. [CrossRef]

11. Arora, R.C.; Chatterjee, S.; Shake, J.G.; Hirose, H.; Engelman, D.T.; Rabin, J.; Firstenberg, M.; Moosdorf, R.G.H.; Geller, C.M.; Hiebert, B.; et al. Survey of Contemporary Cardiac Surgery Intensive Care Unit Models in the United States. Ann. Thorac. Surg. 2020, 109, 702-710. [CrossRef] [PubMed]

12. Benoit, M.A.; Bagshaw, S.M.; Norris, C.M.; Zibdawi, M.; Chin, W.D.; Ross, D.B.; Van Diepen, S. Postoperative complications and outcomes associated with a transition to 24/7 intensivist management of cardiac surgery patients. Crit. Care Med. 2017, 45, 993-1000. [CrossRef] [PubMed]

13. Kumar, K.; Zarychanski, R.; Bell, D.D.; Manji, R.; Zivot, J.; Menkis, A.H.; Arora, R.C. Impact of 24-Hour In-House Intensivists on a Dedicated Cardiac Surgery Intensive Care Unit. Ann. Thorac. Surg. 2009, 88, 1153-1161. [CrossRef] 
14. Rahmanian, P.B.; Kröner, A.; Langebartels, G.; Özel, O.; Wippermann, J.; Wahlers, T. Impact of major non-cardiac complications on outcome following cardiac surgery procedures: Logistic regression analysis in a very recent patient cohort. Interact. Cardiovasc. Thorac. Surg. 2013, 17, 319-327. [CrossRef]

15. Pimentel, M.F.; Soares, M.J.F.; Junior, J.A.M.; de Oliveira, M.A.B.; Faria, F.L.; Faveri, V.Z.; Iano, Y.; Guido, R.C. Predictive Factors of Long-Term Stay in the ICU after Cardiac Surgery: Logistic CASUS Score, Serum Bilirubin Dosage and Extracorporeal Circulation Time. Braz. J. Cardiovasc. Surg. 2017, 32, 367-371. [CrossRef]

16. Albanesi, B.; Nania, T.; Barello, S.; Villa, G.; Rosa, D.; Caruso, R.; Udugampolage, N.S.; Casole, L.; Dellafiore, F. Lived experience of patients in after cardiac surgery: A phenomenological study. Nurs. Crit. Care 2020. [CrossRef]

17. Kolat, P.; Guttenberger, P.; Ried, M.; Kapahnke, J.; Haneya, A.; Schmid, C.; Diez, C. ICU Readmission after Cardiac Surgery—Still a Matter of Concern? Thorac. Cardiovasc. Surg. 2020, 68, 384-388. [CrossRef]

18. Latif, A.; Kruer, R.; Jarrell, A. Reducing medication errors in critical care: A multimodal approach. Clin. Pharmacol. Adv. Appl. 2014, 6, 117-126. [CrossRef]

19. Martinez, E.A.; Shore, A.; Colantuoni, E.; Herzer, K.; Thompson, D.A.; Gurses, A.P.; Marsteller, J.A.; Bauer, L.; Goeschel, C.A.; Cleary, K.; et al. Cardiac surgery errors: Results from the UK National Reporting and Learning System. Int. J. Qual. Heal. Care 2011, 23, 151-158. [CrossRef]

20. Farzi, S.; Irajpour, A.; Saghaei, M.; Ravaghi, H. Causes of medication errors in intensive care units from the perspective of healthcare professionals. J. Res. Pharm. Pract. 2017, 6, 158-165. [CrossRef] [PubMed]

21. Martínez-Romero, M.; Vázquez-Naya, J.M.; Pereira, J.; Pereira, M.; Pazos, A.; Baños, G. The iOSC3 System: Using Ontologies and SWRL Rules for Intelligent Supervision and Care of Patients with Acute Cardiac Disorders. Comput. Math. Methods Med. 2013, 2013, 650671. [CrossRef]

22. Chi, C.-L.; Street, W.N.; Katz, D.A. A decision support system for cost-effective diagnosis. Artif. Intell. Med. 2010, 50, 149-161. [CrossRef]

23. Kindle, R.D.; Badawi, O.; Celi, L.A.; Sturland, S. Intensive Care Unit Telemedicine in the Era of Big Data, Artificial Intelligence, and Computer Clinical Decision Support Systems. Crit. Care Clin. 2019, 35, 483-495. [CrossRef] [PubMed]

24. Schuh, C.; de Bruin, J.S.; Seeling, W. Clinical decision support systems at the Vienna General Hospital using Arden Syntax: Design, implementation, and integration. Artif. Intell. Med. 2018, 92, 24-33. [CrossRef]

25. Fernandes, M.; Vieira, S.M.; Leite, F.; Palos, C.; Finkelstein, S.; Sousa, J.M.C. Clinical Decision Support Systems for Triage in the Emergency Department using Intelligent Systems: A Review. Artif. Intell. Med. 2020, 102, 101762. [CrossRef] [PubMed]

26. Johnson, A.E.W.; Ghassemi, M.M.; Nemati, S.; Niehaus, K.E.; Clifton, D.; Clifford, G.D. Machine Learning and Decision Support in Critical Care. Proc. IEEE 2016, 104, 444-466. [CrossRef]

27. Sidey-Gibbons, J.A.M.; Sidey-Gibbons, C.J. Machine learning in medicine: A practical introduction. BMC Med. Res. Methodol. 2019, 19, 64. [CrossRef] [PubMed]

28. Osheroff, J. Improving Outcomes with Clinical Decision Support; HIMSS Publishing: Boca Ratón, FL, USA, $2012 ;$ ISBN 9781498757461.

29. Tygesen, H.; Eriksson, H.; Herlitz, J. Clinical decision support system (CDSS)—Effects on care quality. Int. J. Health Care Qual. Assur. 2014, 27, 707-718. [CrossRef]

30. Fan, Y.; Zhao, Y.; Li, P.; Liu, X.; Jia, L.; Li, K.; Feng, C.; Pan, F.; Li, T.; Zhang, Z.; et al. Analysis of diseases distribution in Medical Information Mart for Intensive Care III database. Zhonghua Wei Zhong Bing Ji Jiu Yi Xue 2018, 30, 531-537. [CrossRef]

31. Celi, L.; Hinske, L.C.; Alterovitz, G.; Szolovits, P. An artificial intelligence tool to predict fluid requirement in the intensive care unit: A proof-of-concept study. Crit. Care 2008, 12, R151. [CrossRef]

32. Bashar, S.K.; Hossain, M.B.; Ding, E.; Walkey, A.J.; McManus, D.D.; Chon, K.H. Atrial Fibrillation Detection During Sepsis: Study on MIMIC III ICU Data. IEEE J. Biomed. Heal. Inform. 2020, 24, 3124-3135. [CrossRef] [PubMed]

33. Lin, C.-P.; Payne, T.H.; Nichol, W.P.; Hoey, P.J.; Anderson, C.L.; Gennari, J.H. Evaluating Clinical Decision Support Systems: Monitoring CPOE Order Check Override Rates in the Department of Veterans Affairs' Computerized Patient Record System. J. Am. Med. Inform. Assoc. 2008, 15, 620-626. [CrossRef] [PubMed]

34. Wong, A.; Amato, M.G.; Seger, D.L.; Rehr, C.; Wright, A.; Slight, S.P.; Beeler, P.E.; Orav, E.J.; Bates, D.W. Prospective evaluation of medication-related clinical decision support over-rides in the intensive care unit. BMJ Qual. Saf. 2018, 27, 718-724. [CrossRef]

35. Cresswell, K.; Mozaffar, H.; Shah, S.; Sheikh, A. Approaches to promoting the appropriate use of antibiotics through hospital electronic prescribing systems: A scoping review. Int. J. Pharm. Pract. 2017, 25, 5-17. [CrossRef]

36. Stultz, J.S.; Nahata, M.C. Computerized clinical decision support for medication prescribing and utilization in pediatrics. J. Am. Med. Inform. Assoc. 2012, 19, 942-953. [CrossRef]

37. Jin, B.; Che, C.; Liu, Z.; Zhang, S.; Yin, X.; Wei, X. Predicting the Risk of Heart Failure With EHR Sequential Data Modeling. IEEE Access 2018, 6, 9256-9261. [CrossRef]

38. Dias, D.; Paulo Silva Cunha, J. Wearable Health Devices-Vital Sign Monitoring, Systems and Technologies. Sensors 2018, 18, 2414. [CrossRef] [PubMed]

39. Downing, N.L.; Rolnick, J.; Poole, S.F.; Hall, E.; Wessels, A.J.; Heidenreich, P.; Shieh, L. Electronic health record-based clinical decision support alert for severe sepsis: A randomised evaluation. BMJ Qual. Saf. 2019, 28, 762-768. [CrossRef] [PubMed]

40. Prgomet, M.; Li, L.; Niazkhani, Z.; Georgiou, A.; Westbrook, J.I. Impact of commercial computerized provider order entry (CPOE) and clinical decision support systems (CDSSs) on medication errors, length of stay, and mortality in intensive care units: A systematic review and meta-analysis. J. Am. Med. Inform. Assoc. 2017, 24, 413-422. [CrossRef] 
41. Vermeulen, K.M.; van Doormaal, J.E.; Zaal, R.J.; Mol, P.G.M.; Lenderink, A.W.; Haaijer-Ruskamp, F.M.; Kosterink, J.G.W.; van den Bemt, P.M.L.A. Cost-effectiveness of an electronic medication ordering system (CPOE/CDSS) in hospitalized patients. Int. J. Med. Inform. 2014, 83, 572-580. [CrossRef]

42. Jacob, V.; Thota, A.B.; Chattopadhyay, S.K.; Njie, G.J.; Proia, K.K.; Hopkins, D.P.; Ross, M.N.; Pronk, N.P.; Clymer, J.M. Cost and economic benefit of clinical decision support systems for cardiovascular disease prevention: A community guide systematic review. J. Am. Med. Inform. Assoc. 2017, 24, 669-676. [CrossRef] [PubMed]

43. Njie, G.J.; Proia, K.K.; Thota, A.B.; Finnie, R.K.C.; Hopkins, D.P.; Banks, S.M.; Callahan, D.B.; Pronk, N.P.; Rask, K.J.; Lackland, D.T.; et al. Clinical Decision Support Systems and Prevention. Am. J. Prev. Med. 2015, 49, 784-795. [CrossRef] [PubMed]

44. Fillmore, C.L.; Bray, B.E.; Kawamoto, K. Systematic review of clinical decision support interventions with potential for inpatient cost reduction. BMC Med. Inform. Decis. Mak. 2013, 13. [CrossRef] [PubMed]

45. Ann McKibbon, K.; Lokker, C.; Handler, S.M.; Dolovich, L.R.; Holbrook, A.M.; O’Reilly, D.; Tamblyn, R.; Hemens, B.J.; Basu, R.; Troyan, S.; et al. The effectiveness of integrated health information technologies across the phases of medication management: A systematic review of randomized controlled trials. J. Am. Med. Informatics Assoc. 2012, 19, 22-30. [CrossRef]

46. Sutton, R.T.; Pincock, D.; Baumgart, D.C.; Sadowski, D.C.; Fedorak, R.N.; Kroeker, K.I. An overview of clinical decision support systems: Benefits, risks, and strategies for success. npj Digit. Med. 2020, 3, 17. [CrossRef]

47. Chuo, J.; Hicks, R.W. Computer-Related Medication Errors in Neonatal Intensive Care Units. Clin. Perinatol. 2008, 35, 119-139. [CrossRef]

48. MacK, E.H.; Wheeler, D.S.; Embi, P.J. Clinical decision support systems in the pediatric intensive care unit. Pediatr. Crit. Care Med. 2009, 10, 23-28. [CrossRef]

49. York, J.B.; Cardoso, M.Z.; Azuma, D.S.; Beam, K.S.; Binney, G.G.; Weingart, S.N. Computerized Physician Order Entry in the Neonatal Intensive Care Unit: A Narrative Review. Appl. Clin. Inform. 2019, 10, 487-494. [CrossRef] [PubMed]

50. Moher, D.; Shamseer, L.; Clarke, M.; Ghersi, D.; Liberati, A.; Petticrew, M.; Shekelle, P.; Stewart, L.A. Preferred reporting items for systematic review and meta-analysis protocols (PRISMA-P) 2015 statement. Syst. Rev. 2015, 4, 1. [CrossRef]

51. Banner, M.J.; Euliano, N.R.; MacIntyre, N.R.; Layon, A.J.; Bonett, S.; Gentile, M.A.; Bshouty, Z.; Peters, C.; Gabrielli, A. Ventilator Advisory System Employing Load and Tolerance Strategy Recommends Appropriate Pressure Support Ventilation Settings. Chest 2008, 133, 697-703. [CrossRef]

52. Campion, T.R.; May, A.K.; Waitman, L.R.; Ozdas, A.; Lorenzi, N.M.; Gadd, C.S. Characteristics and effects of nurse dosing over-rides on computer-based intensive insulin therapy protocol performance. J. Am. Med. Inform. Assoc. 2011, 18, 251-258 [CrossRef]

53. Denaï, M.A.; Mahfouf, M.; Ross, J.J. A hybrid hierarchical decision support system for cardiac surgical intensive care patients. Part I: Physiological modelling and decision support system design. Artif. Intell. Med. 2009, 45, 35-52. [CrossRef] [PubMed]

54. Hsu, J.-C.; Chen, Y.-F.; Chung, W.-S.; Tan, T.-H.; Chen, T.; Chiang, J.Y. Clinical Verification of A Clinical Decision Support System for Ventilator Weaning. Biomed. Eng. Online 2013, 12, S4. [CrossRef]

55. Jalali, A.; Bender, D.; Rehman, M.; Nadkanri, V.; Nataraj, C. Advanced analytics for outcome prediction in intensive care units. In Proceedings of the 2016 38th Annual International Conference of the IEEE Engineering in Medicine and Biology Society (EMBC), Orlando, FL, USA, 16-20 August 2016; pp. 2520-2524.

56. Jalali, A.; Simpao, A.F.; Gálvez, J.A.; Licht, D.J.; Nataraj, C. Prediction of Periventricular Leukomalacia in Neonates after Cardiac Surgery Using Machine Learning Algorithms. J. Med. Syst. 2018, 42, 177. [CrossRef]

57. Kallet, R.H.; Branson, R.D. Respiratory controversies in the critical care setting. Do the NIH ARDS Clinical Trials Network PEEP/FIO2 tables provide the best evidence-based guide to balancing PEEP and FIO2 settings in adults? Respir. Care 2007, 52, 461-475; discussion 475-477.

58. May, L.J.; Longhurst, C.A.; Pageler, N.M.; Wood, M.S.; Sharek, P.J.; Zebrack, C.M. Optimizing Care of Adults With Congenital Heart Disease in a Pediatric Cardiovascular ICU Using Electronic Clinical Decision Support. Pediatr. Crit. Care Med. 2014, 15, 428-434. [CrossRef] [PubMed]

59. Ross, J.J.; Denaï, M.A.; Mahfouf, M. A hybrid hierarchical decision support system for cardiac surgical intensive care patients. Part II. Clinical implementation and evaluation. Artif. Intell. Med. 2009, 45, 53-62. [CrossRef]

60. Sintchenko, V.; Coiera, E. Decision complexity affects the extent and type of decision support use. In AMIA Annual Symposium Proceedings; American Medical Informatics Association: Bethesda, MD, USA, 2006; pp. 724-728.

61. Sondergaard, S.; Wall, P.; Cocks, K.; Parkin, W.G.; Leaning, M.S. High concordance between expert anaesthetists' actions and advice of decision support system in achieving oxygen delivery targets in high-risk surgery patients. Br. J. Anaesth. 2012, 108, 966-972. [CrossRef]

62. Thompson, B.T.; Orme, J.F.; Zheng, H.; Luckett, P.M.; Truwit, J.D.; Willson, D.F.; Hite, R.D.; Brower, R.G.; Bernard, G.R.; Curley, M.A.Q.; et al. Multicenter Validation of a Computer-Based Clinical Decision Support Tool for Glucose Control in Adult and Pediatric Intensive Care Units. J. Diabetes Sci. Technol. 2008, 2, 357-368. [CrossRef] [PubMed]

63. Warrick, C.; Naik, H.; Avis, S.; Fletcher, P.; Franklin, B.D.; Inwald, D. A clinical information system reduces medication errors in paediatric intensive care. Intensive Care Med. 2011, 37, 691-694. [CrossRef] [PubMed] 
64. Zaslansky, R.; Rothaug, J.; Chapman, R.C.; Backström, R.; Brill, S.; Engel, C.; Fletcher, D.; Fodor, L.; Funk, P.; Gordon, D.; et al. PAIN OUT: An international acute pain registry supporting clinicians in decision making and in quality improvement activities. J. Eval. Clin. Pract. 2014, 20, 1090-1098. [CrossRef]

65. Aushev, A.; Ripoll, V.R.; Vellido, A.; Aletti, F.; Pinto, B.B.; Herpain, A.; Post, E.H.; Medina, E.R.; Ferrer, R.; Baselli, G.; et al. Feature selection for the accurate prediction of septic and cardiogenic shock ICU mortality in the acute phase. PLoS ONE 2018, 13, e0199089. [CrossRef]

66. Johnson, A.E.W.; Pollard, T.J.; Shen, L.; Lehman, L.H.; Feng, M.; Ghassemi, M.; Moody, B.; Szolovits, P.; Anthony Celi, L.; Mark, R.G. MIMIC-III, a freely accessible critical care database. Sci. Data 2016, 3, 160035. [CrossRef] [PubMed]

67. Saeed, M.; Villarroel, M.; Reisner, A.T.; Clifford, G.; Lehman, L.-W.; Moody, G.; Heldt, T.; Kyaw, T.H.; Moody, B.; Mark, R.G. Multiparameter Intelligent Monitoring in Intensive Care II: A public-access intensive care unit database. Crit. Care Med. 2011, 39, 952-960. [CrossRef]

68. Rojas, J.C.; Carey, K.A.; Edelson, D.P.; Venable, L.R.; Howell, M.D.; Churpek, M.M. Predicting Intensive Care Unit Readmission with Machine Learning Using Electronic Health Record Data. Ann. Am. Thorac. Soc. 2018, 15, 846-853. [CrossRef]

69. Armada, E.R.; Villamañán, E.; López-de-Sá, E.; Rosillo, S.; Rey-Blas, J.R.; Testillano, M.L.; Álvarez-Sala, R.; López-Sendón, J. Computerized physician order entry in the cardiac intensive care unit: Effects on prescription errors and workflow conditions. J. Crit. Care 2014, 29, 188-193. [CrossRef] [PubMed]

70. Gouyon, B.; Iacobelli, S.; Saliba, E.; Quantin, C.; Pignolet, A.; Jacqz-Aigrain, E.; Gouyon, J.B. A Computer Prescribing Order Entry-Clinical Decision Support system designed for neonatal care: Results of the 'preselected prescription' concept at the bedside. J. Clin. Pharm. Ther. 2017, 42, 64-68. [CrossRef]

71. Vardi, A.; Efrati, O.; Levin, I.; Matok, I.; Rubinstein, M.; Paret, G.; Barzilay, Z. Prevention of potential errors in resuscitation medications orders by means of a computerised physician order entry in paediatric critical care. Resuscitation 2007, 73, 400-406. [CrossRef] [PubMed]

72. Wulff, A.; Haarbrandt, B.; Tute, E.; Marschollek, M.; Beerbaum, P.; Jack, T. An interoperable clinical decision-support system for early detection of SIRS in pediatric intensive care using openEHR. Artif. Intell. Med. 2018, 89, 10-23. [CrossRef]

73. Khalifa, M.; Magrabi, F.; Gallego, B. Developing a framework for evidence-based grading and assessment of predictive tools for clinical decision support. BMC Med. Inform. Decis. Mak. 2019, 19, 207. [CrossRef]

74. Myssiorek, D.; Ahmed, Y.; Parsikia, A.; Castaldi, M.; McNelis, J. Factors predictive of the development of surgical site infection in thyroidectomy-An analysis of NSQIP database. Int. J. Surg. 2018, 60, 273-278. [CrossRef]

75. Wessler, B.S.; Lai YH, L.; Kramer, W.; Cangelosi, M.; Raman, G.; Lutz, J.S.; Kent, D.M. Clinical Prediction Models for Cardiovascular Disease. Circ. Cardiovasc. Qual. Outcomes 2015, 8, 368-375. [CrossRef] [PubMed]

76. Elshayib, M.; Pawola, L. Computerized provider order entry-related medication errors among hospitalized patients: An integrative review. Health Inform. J. 2020, 26, 2834-2859. [CrossRef] [PubMed]

77. Manias, E.; Kusljic, S.; Wu, A. Interventions to reduce medication errors in adult medical and surgical settings: A systematic review. Ther. Adv. Drug Saf. 2020, 11, 204209862096830. [CrossRef]

78. Kinlay, M.; Zheng, W.Y.; Burke, R.; Juraskova, I.; Moles, R.; Baysari, M. Medication errors related to computerized provider order entry systems in hospitals and how they change over time: A narrative review. Res. Soc. Adm. Pharm. 2020. [CrossRef] [PubMed]

79. Sutherland, A.; Canobbio, M.; Clarke, J.; Randall, M.; Skelland, T.; Weston, E. Incidence and prevalence of intravenous medication errors in the UK: A systematic review. Eur. J. Hosp. Pharm. 2020, 27, 3-8. [CrossRef]

80. Hosseini-Marznaki, Z.; Pouy, S.; Salisu, W.J.; Emami Zeydi, A. Medication errors among Iranian emergency nurses: A systematic review. Epidemiol. Health 2020, 42, e2020030. [CrossRef] 